\title{
Design of a bonnet of a sport vehicle realized with an innovative recyclable Polymeric Matrix Composite and virtual characterization of the related sandwich structure
}

\author{
Basso M. ${ }^{1}$, Mingazzini $C .{ }^{2}$, Scafè $M .^{2}$, Leoni E. ${ }^{2}$, Benco E. ${ }^{3}$, Garcia-Etxabe ${ }^{4}{ }^{4}$, Gondra ${ }^{4}{ }^{4}$, \\ Pullini ${ }^{l}{ }^{l}$ \\ ${ }^{1}$ STELLANTIS-Materials Engineering Methods \& Tools (CRF). Turin and Naples, Italy \\ ${ }^{2}$ ENEA SSPT-PROMAS-TEMAF, Faenza RA, Italy \\ ${ }^{3} \mathrm{GS} 4 \mathrm{C}$ srl, Milano, Italy \\ ${ }^{4}$ GAIKER Technology Centre, Basque Research and Technology Alliance (BRTA), Spain
}

\begin{abstract}
This article presents the design activities of an automotive component to be produced using a recyclable cleavable-epoxy Matrix Composite and Basalt-Derived Mineral Fibres. The material innovations are being studied within project $\mathrm{C} 2 \mathrm{CC}$ (www.c2cc-project.eu), aimed at satisfying latest EU directives regarding end-of-life reuse and C-footprint reduction. The main targets are the weight reduction, obtained employing materials with lower footprint, namely a biomass derived epoxy and a cradle-to-cradle recyclable mineral fiber, that is a fibre that (differently from carbon fibre) can be remelted to long fibre with no decrease in mechanical specifications [1]. For recycling both the resin and the fibre, a the cleavable hardener was adopted [2] developed by Connnora Inc (US), which avoids the need of pyrolysis to recover and recycle the fibers from prepreg scraps and end-of-life components. The main project demonstrator is the front bonnet of segment A vehicle FIAT 500 Abarth. One approach to reach the component expected performances is using the semifinished composite materials (prepregs) produced by the project to manufacture a final structural sandwich. From the modelling point of view, this work carries out a multiscale approach starting from the basic constituents of skin and core and ending with the model at the mesoscale of the specimens of the sandwich. The simulation activity was conducted considering the possible recyclable sandwich cores, and the comparison aims at selecting the optimal ones for this specific automotive component.
\end{abstract}




\section{Introduction}

This article presents the activities conducted by CRF about the Design and the Virtual testing of the front bonnet demonstrator, the first and more important one expected within $\mathrm{C} 2 \mathrm{CC}$ project. $\mathrm{C} 2 \mathrm{CC}$ project aims at producing recyclable polymeric composites (PMC), in compliance with End-of-Life Vehicles (ELV) regulations. In these composites the reinforce fibres will be derived from basalt (BDMF, Basalt Derived Mineral Fibres which are cradleto cradle $(\mathrm{C} 2 \mathrm{C})$ recyclable, meaning they can be recycled and reused for the original applications, since no performance loss is expected by remelting. These innovative aeronautical grade fibres were associated to a a biomass-derived epoxy cured adding a cleavable hardener [3-5] which can be leached in acetic acid solutions to recover a thermoplastic compound

\subsection{Front bonnet PMC Demonstrator}

The automotive demonstrator chosen by CRF is a front bonnet, being the most critical of all "closures" elements, being subjected to both insulation and the heat produced by the internal combustion engine. Heat can be a major threat for innovative PMC, since it accelerates degradation and reduces mechanical performances. Within the project, the "sandwich type" demonstrator is not supported by a PMC frame, but flexural strength of the solution depends on the use of with a recyclable core reinforcement (Fig. 1).

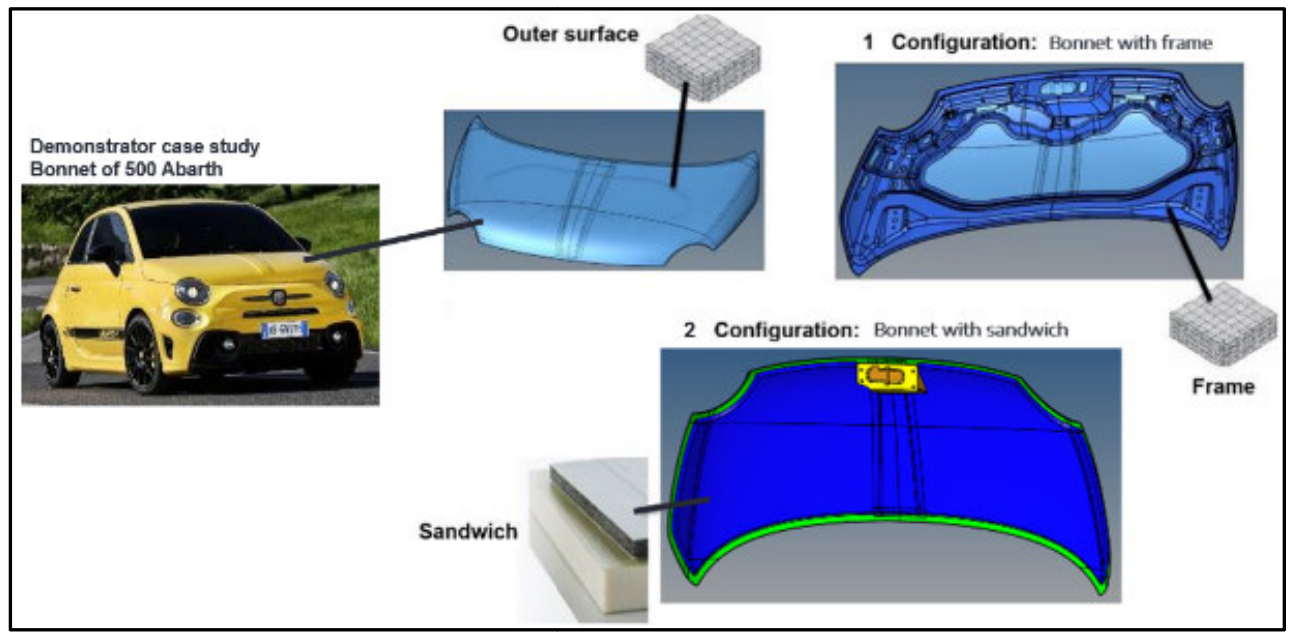

Fig. 1. Automotive Demonstrator

\subsection{Design and Simulations activities}

Design and simulation activities in $\mathrm{C} 2 \mathrm{CC}$ aimed at checking that main Stellantis automotive requirements were fulfilled. To reach this target, $\mathrm{C} 2 \mathrm{CC}$ started focusing on static performance, since these are undoubtedly the main requirements that any engine bonnet has to guarantee (see following paragraph 3 ).

The development activity dealt with the following sequence of aspects. (i) Definition of the lamination sequence; (ii) Mechanical tests for the characterisation of the innovative composite material (performed by ENEA); (iii) Set the inputs for mechanical model using the mechanical performances of the innovative composite material as input; (iv) analysis of 
the static performance of the front bonnet, and verify the satisfaction of Stellantis standard requirements. All these aspects have been realized through virtual analysis.

\section{Design of the 500 Abarth engine bonnet}

The innovative material developed in $\mathrm{C} 2 \mathrm{CC}$ project (recyclable $\mathrm{PMC}$ prepreg), is a polymer matrix composite based on cleavable epoxies and reinforced with continuous BDMF. The polymer matrix characteristics determine the maximum operating temperature (that is the $\max \mathrm{T}$ at which the component can be used for a structural function).

\section{Modelling and Virtual characterization of composite sandwich}

A sandwich-structural composite is obtained by associating two thin but stiff skins to a lightweight but thick core. The core material is normally a low strength material, but the design ensures that a higher thickness provides to the sandwich composite a higher bending strength. Open- and closed-cell-semi-structural synthetic foams (such as polyether sulfone polyvinyl chloride, polyurethane, polyethylene or polystyrene ones), natural balsa wood, metal foam and honeycombs were considered as possible core materials, finally a PET foam has been chosen (considering that in prospect it will be produced from recycled PET, which is an abundant secondary raw material). Laminates of glass or carbon fiber, with thermoplastic or thermoset matrix are generally used for the outer skins [6]. Core and skins are then bonded using a structural adhesive (Fig. 2) or joined together in another way.

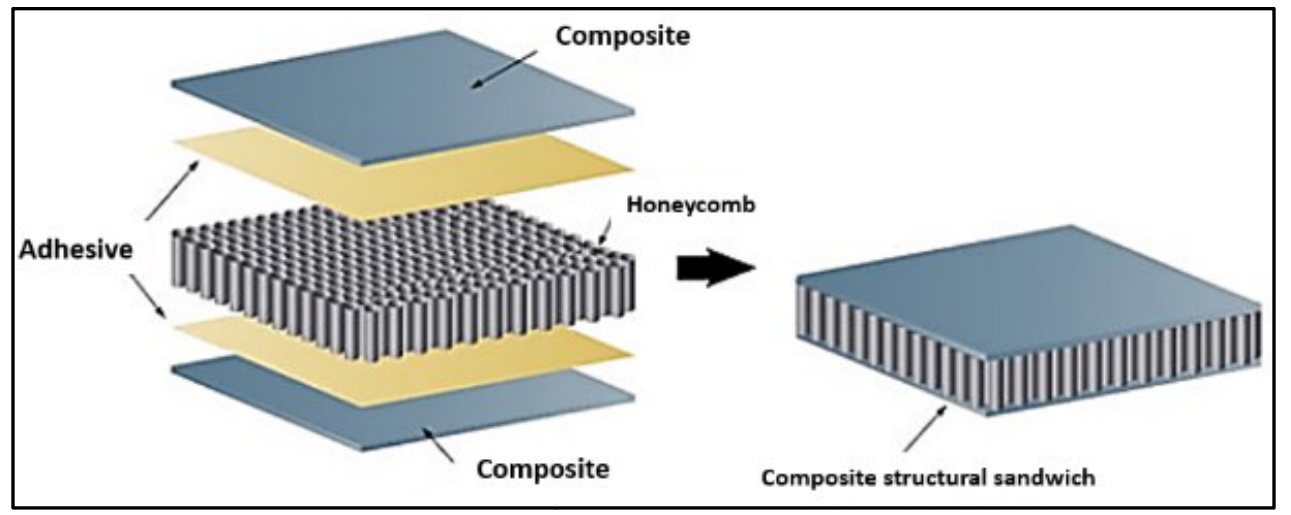

Fig. 2. Sandwich-structural composite

In the case of the front bonnet of the 500 Abarth, in "sandwich" configuration, the material choice aims the total recyclability of the EoL bonnet, recovering all the materials used. Regarding the core, the more effective and yet the more environmentally friendly solutions seem those based secondary raw materials. One considered material was a Filava Felt, reemploying the same fibre that can be recovered by the EoL treatment of $\mathrm{C} 2 \mathrm{CC}$ innovative PMC. This felt was produced and characterised by ENEA in C2CC project: since their compression strength is really limited compared to other solutions, the aim of modelling is calculating the expected strength of the front bonnet and satisfaction of the requirements of Stellantis quality standards. The first step of modelling decides the thickness of the layers in 
the composite sandwich using a commercial software specifically developed for this type of evaluations [7-8].

\subsection{Materials}

The mechanical properties of the materials used in all the virtual analysis were determined both through experimental activities and compared with data from the scientific literature. As a consequence, this experimental activity of mechanical measures is necessary at the very beginning of every modelling activity. In $\mathrm{C} 2 \mathrm{CC}$ project, the activity was performed along with prepreg and cleavable epoxies optimisation and then conducted iteratively up to optimisation of the overall solution. The properties of the developed materials are collected in Table 1.

Table 1. Materials Properties.

\begin{tabular}{|c|c|c|c|}
\hline Properties & & $\begin{array}{c}\text { Filava } \\
\text { Felt }\end{array}$ & $\begin{array}{c}\text { PET } \\
\text { foam }\end{array}$ \\
\hline $\begin{array}{c}\text { Compressive } \\
\text { Strength }\end{array}$ & $\mathrm{X}_{\mathrm{c}}[\mathrm{MPa}]$ & 0.02 & 0.72 \\
\hline $\begin{array}{c}\text { Shear } \\
\text { Strength }\end{array}$ & $\mathrm{S}[\mathrm{MPa}]$ & 0.58 & 0.49 \\
\hline $\begin{array}{c}\text { Tensile } \\
\text { Modulus }\end{array}$ & $\mathrm{E}_{\mathrm{t}}[\mathrm{MPa}]$ & 0.136 & \\
\hline $\begin{array}{c}\text { Compressive } \\
\text { Modulus }\end{array}$ & $\mathrm{E}_{\mathrm{c}}[\mathrm{MPa}]$ & & 65 \\
\hline Density & $\rho_{\mathrm{f}}\left[\mathrm{g} / \mathrm{cm}^{3}\right]$ & 1.12 & 0.065 \\
\hline Poisson ratio & $v_{f}$ & 0.3 & \\
\hline
\end{tabular}

\begin{tabular}{|c|c|c|}
\hline Properties & $\begin{array}{c}\text { C2CC 600gsm } \\
\text { Epoxy } \\
\left(\mathbf{V}_{\mathrm{f}}=\mathbf{0 . 4}\right)\end{array}$ \\
\hline $\begin{array}{c}\text { Tensile } \\
\text { Modulus Warp }\end{array}$ & $\mathrm{E}_{1 \mathrm{t}}[\mathrm{MPa}]$ & 21500 \\
\hline $\begin{array}{c}\text { Tensile } \\
\text { Modulus Weft }\end{array}$ & $\mathrm{E}_{2 \mathrm{t}}[\mathrm{MPa}]$ & 21500 \\
\hline $\begin{array}{c}\text { Tensile } \\
\text { Strength Warp }\end{array}$ & $\mathrm{X}_{\mathrm{t}}[\mathrm{MPa}]$ & 504 \\
\hline $\begin{array}{c}\text { Tensile } \\
\text { Strength Weft }\end{array}$ & $\mathrm{Y}_{\mathrm{t}}[\mathrm{MPa}]$ & 504 \\
\hline $\begin{array}{c}\text { Compressive } \\
\text { Modulus Warp }\end{array}$ & $\mathrm{E}_{1 \mathrm{c}}[\mathrm{MPa}]$ & 23500 \\
\hline $\begin{array}{c}\text { Compressive } \\
\text { Modulus Weft }\end{array}$ & $\mathrm{E}_{2 \mathrm{c}}[\mathrm{MPa}]$ & 23500 \\
\hline $\begin{array}{c}\text { Compressive } \\
\text { Strength Warp }\end{array}$ & $\mathrm{X}_{\mathrm{c}}[\mathrm{MPa}]$ & 262 \\
\hline $\begin{array}{c}\text { Compressive } \\
\text { Strength Weft }\end{array}$ & $\mathrm{Y}_{\mathrm{c}}[\mathrm{MPa}]$ & 262 \\
\hline Shear Modulus & $\mathrm{G}_{12}[\mathrm{MPa}]$ & 2800 \\
\hline Shear Strength & $\mathrm{S}_{12}[\mathrm{MPa}]$ & 45 \\
\hline Poisson ratio & $\mathrm{v}_{12}$ & 0.086 \\
\hline Density & $\boldsymbol{\rho}[\mathrm{g} / \mathrm{cm}]$ & 1.72 \\
\hline
\end{tabular}

\subsection{Multiscale modelling of the composite sandwich}

The virtual characterization of the composite sandwiches applied a multiscale approach to the material modelling. At micromechanics level, each constituent in the specimen was modelled separately: namely the composite laminate, the core (foam or felt) and the interface between skin and core. Then, at mesoscale level, the specimens were virtual characterized considering a 4-point bending test. Then, at macroscale level, all these results can be exploited into the FEM model of the front Bonnet (Fig. 3).

In the modelling of the composite sandwich for the front bonnet configuration, with a micromechanics model of the woven twill $2 \times 2$, it is possible to determine the mechanical characteristic with a good correlation with the experimental data. With the 
micromechanical model of the polymer, is possible to determine the stress-strain curve of the sandwich core (Fig.4). It must be highlighted the large difference between the curves of felt and PET, behaviour that has a big influence on the specimens. Regarding the interface layer between the skin and the core of the sandwich, in first approximation (and for improved environmental sustainability), the same recyclable matrix used for the PMC prepreg is considered, which further reduces performances compared to the possible use of a structural adhesive but makes the closed loop recycling of the End-of-Life component easier. $\mathrm{C} 2 \mathrm{CC}$ project focuses on weight reduction in the automotive, but also to PMC cradle-to-cradle recycling, meaning recycling produces materials which can be reused for the original applications, without performance loss. This in this case was proved regarding the BDMF reinforcement.

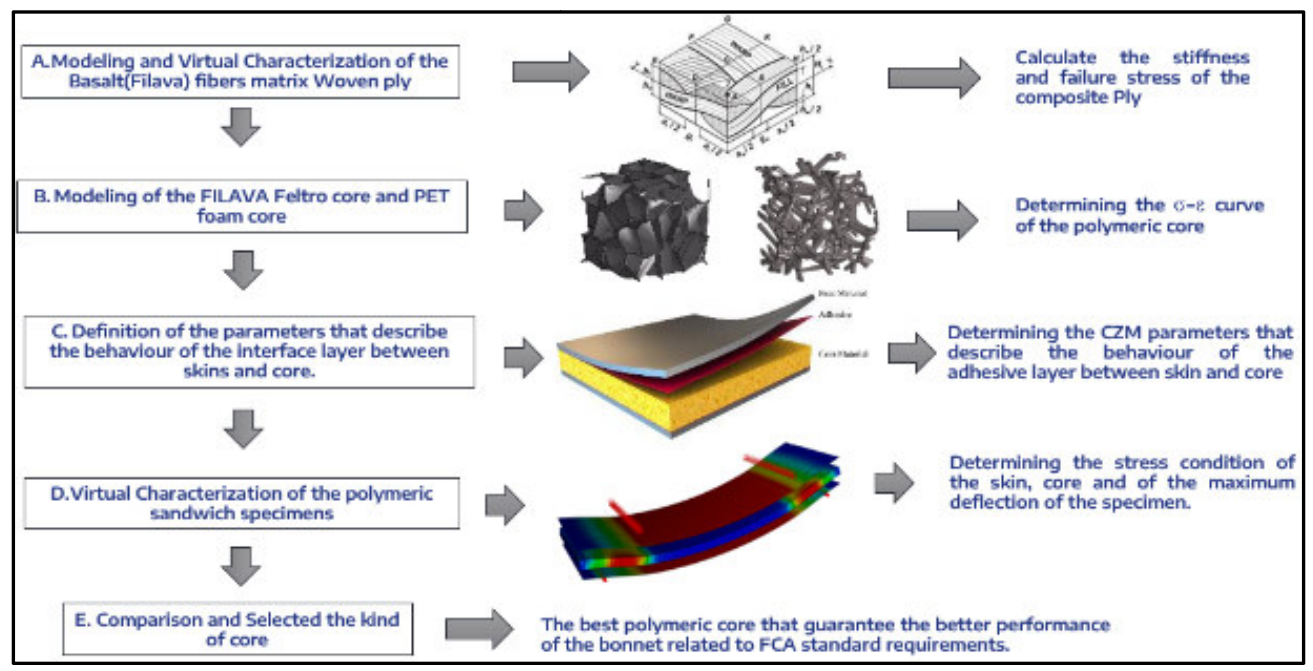

Fig. 3. Multiscale approach in $\mathrm{C} 2 \mathrm{CC}$ Project

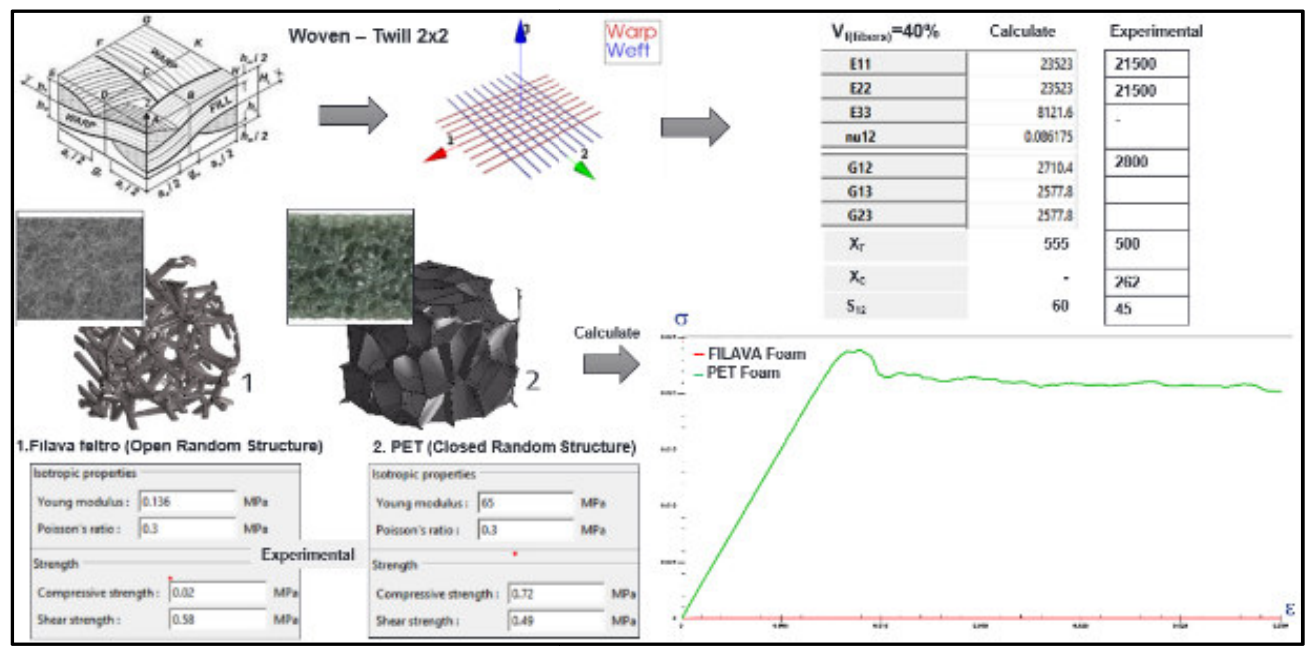

Fig. 4. Outputs of the Multiscale process 


\subsection{Load cases}

In $\mathrm{C} 2 \mathrm{CC}$, the front bonnet of the 500 Abarth is being developed, aiming at showing the possibility of producing $\mathrm{C} 2 \mathrm{C}$ recyclable demonstrator satisfying main Stellantis requirements. For this scope, the basic qualification standards, in terms of the static performance that a generic bonnet must achieve, are reported in Table 2.

Table 2. Load Cases.

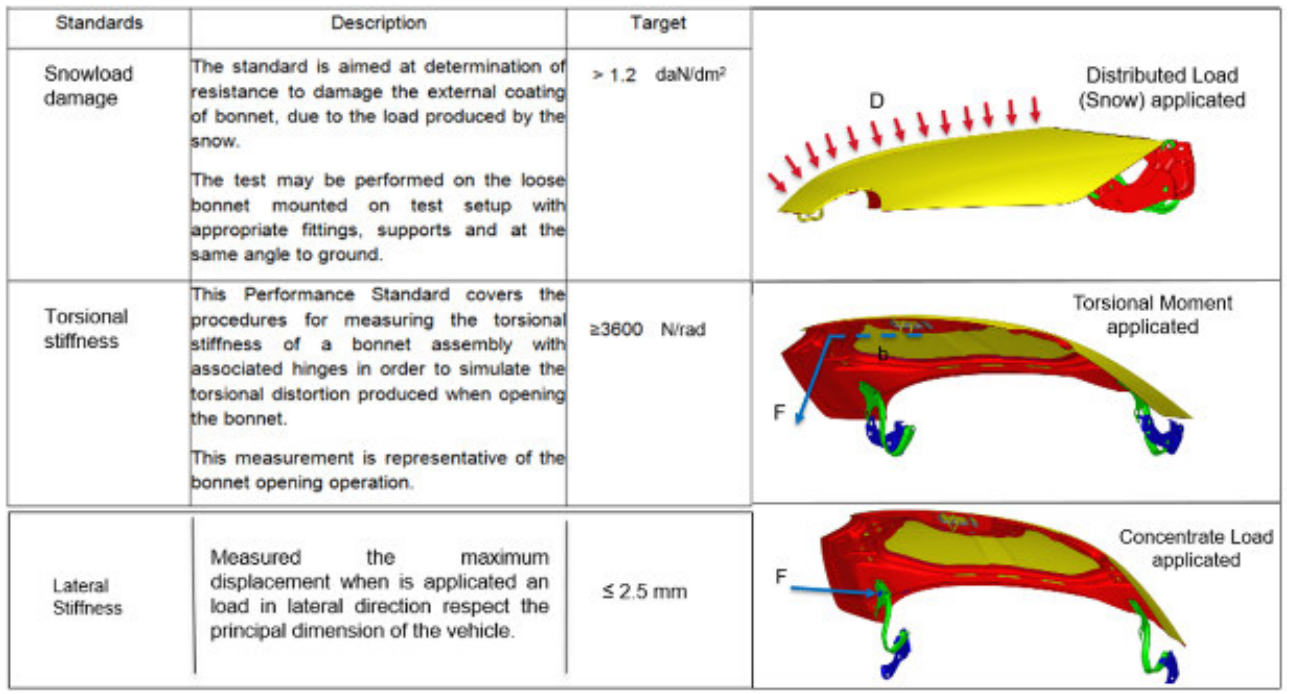

For the characterization of the sandwich specimens, a 4-point bending test was applied. The load case is a concentrated load equivalent to the distributed load required by the Stellantis "snow load damage resistance standard" (Fig. 5).

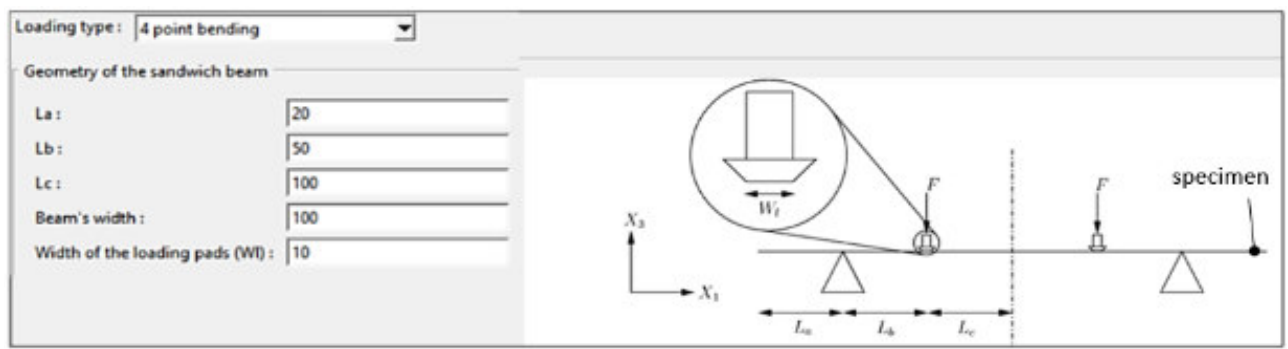

Fig. 5. Load case on sandwich specimen.

\subsection{Virtual Characterization of the composite sandwich}

In Fig. 6, the expected results of the 4-point bending test on composite sandwich based on Filava felt core, with the load reported in Fig. 5, are depicted. A significant inflection of the specimen is predicted. In addition, the core reaches about $85 \%$ of its ultimate strength. Both the conditions are not in line with Stellantis standard requirements. In fact, the standard FCA denominated "snow load damage test", prescribe that the outer surface of the bonnet must support the load without damage. 


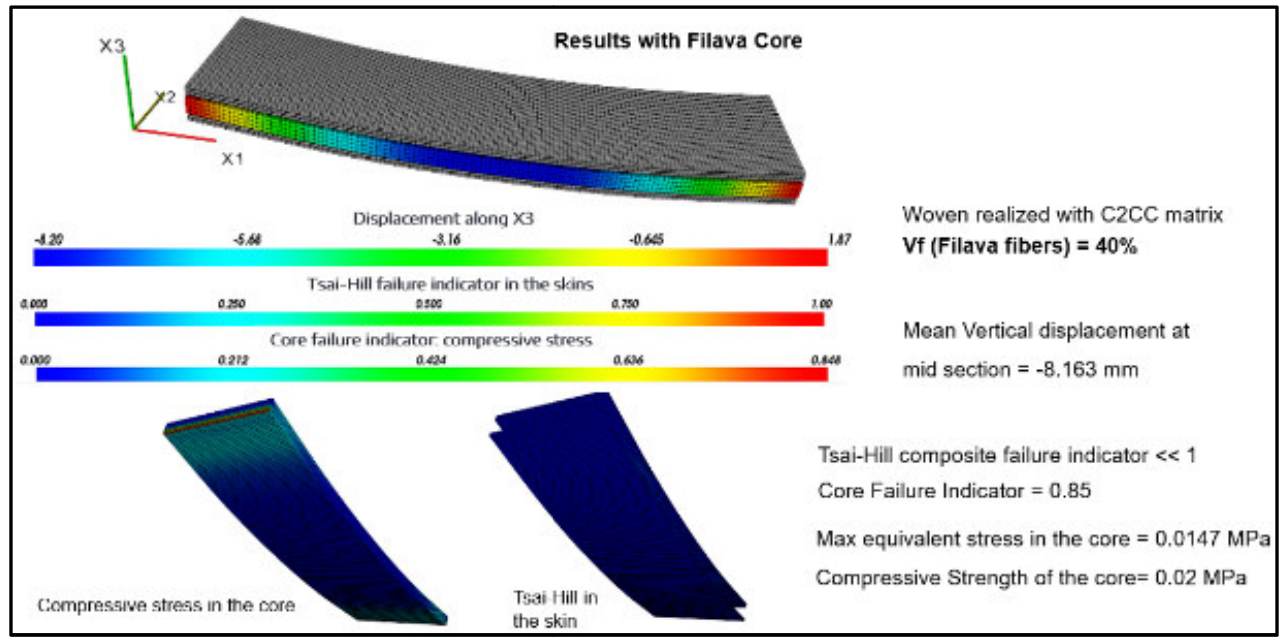

Fig. 6. Results of the 4-point bending test on composite sandwich based on Filava felt core

In Fig. 7, the results of the 4-point bending test on composite sandwich considering a PET core, and the load of the Fig. 5, are reported. The expected inflection is less than $1 \mathrm{~mm}$ and consequently the stress, with the PET foam core, is only $3 \%$ of its ultimate resistance. In conclusion PET foam appears to be an acceptable core-solution, while Filava felts is not. Filava felts might be considered a secondary based product, but it appear not suitable for producing structural components. The study was not brought to the next step (demonstrator manufacturing in $\mathrm{AM})$.

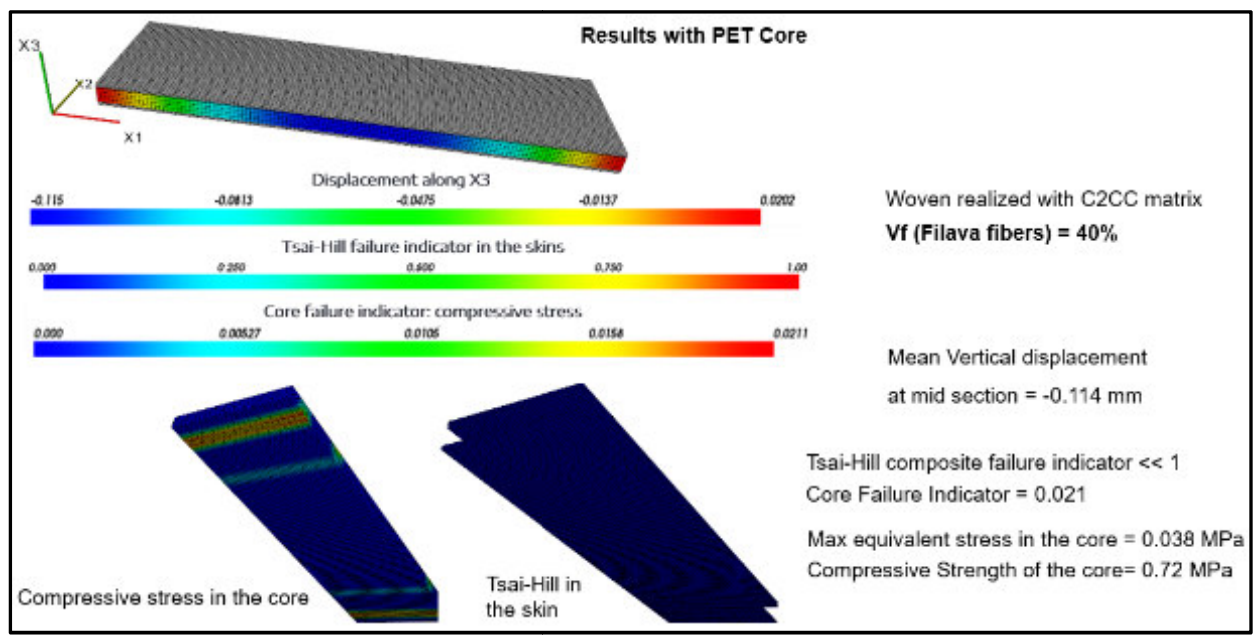

Fig. 7. Results of the 4-point bending test on composite sandwich based on PET foam core

\section{Conclusions}

As part of the $\mathrm{C} 2 \mathrm{CC}$ project, a sport vehicle front bonnet was developed and produced using an innovative recyclable Polymeric Matrix Composite. This bonnet was originally planned in two configurations, a composite sandwich with two different type of 
reinforcement core. In this context, it has been developed a multiscale method for modelling and virtual characterization of the composite sandwich with polymeric core.

The next steps in $\mathrm{C} 2 \mathrm{CC}$ project will be about developing activities on the frame+skin configuration of the same bonnet project demonstrator, aiming at further improvement of performances of employed recyclable Polymeric Matrix Composite and optimisation of the demonstrator design. Furthermore, the sandwich composite modelling method will be completed and validated with comparison with other experimental data. C2CC project is also validating the reuse of recovered thermoplastics for injection molding of automotive internals, which is also very important to exploit recovered thermoplastics. The adoption of the recyclamine technology is extremely interesting also for sector different for the automotive, for example recyclable wind turbine composite blades [9].

\section{References}

1. Cradle-to-Cradle Composites from prepregs: recycle of both the fiber and polymer matrix, Compositi magazine, June 2019, XIV, 52, pag. 34-35.

2. www.adityabirlachemicals.com/brand/recyclamine

3. Innovative Chemical Process for Recycling Thermosets Cured with Recyclamines ${ }^{\circledR}$ by Converting Bio-Epoxy Composites in Reusable Thermoplastic-An LCA Study", en.wikipedia.org/wiki/Sandwich-structured_composite, A. D. La Rosa, I. Blanco, Diosdado R. Banatao, S. J. Pastine, A. Björklund, G. Cicala, Materials (Basel). 2018 Mar; 11(3): 353, doi: 10.3390/ma11030353.

4. Recyclable High Pressure Resin Transfer (hp-rtm) Molding Epoxy Systems and their Composite Properties., 128. Pastine S., Swentek I., Nasrullah M., Kosiński S., Banatao R., Ugresic V., Henning F., www.semanticscholar.org/paper/RECYCLABLE-HIGHPRESSURE-RESIN-TRANSFER-(HP-RTM)-Pastine-

Swentek/4893806602d318e74d41cf794546b993c5ffd358.

5. Connora Technologies Makes Epoxy Truly Recyclable, Composites World, Gardiner G 11/13/2014, www.compositesworld.com/articles/-connora-technologies-makesepoxy-truly-recyclable.

6. Composite Materials Handbook - Volume 6. Structural Sandwich Composites - SAE

7. Abaqus software, www.3ds.com/productsservices/simulia/products/abaqus/abaqusstandard

8. MSC Digimat software, www.mscsoftware.com/it/product/digimat

9. Sustainable End-of-Life Management of Wind Turbine Blades: Overview of Current and Coming Solutions, Leon Mishnaevsky, Jr, Materials (Basel). 2021 Mar; 14(5): 1124, doi: 10.3390/ma14051124.

\section{Acknowledgments}

This was cofunded by EIT RM, within project C2CC, (C2CC-project.eu)

Cradle-to-Cradle Composites (upscaling, 18052, KAVA 5, 2019-2022)

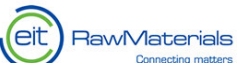

